\title{
Static and vibration analysis of cross-ply laminated composite doubly curved shallow shell panels with stiffeners resting on Winkler-Pasternak elastic foundations
}

\author{
Minh Tu Tran' ${ }^{1}$ Van Loi Nguyen ${ }^{1} \cdot$ Anh Tuan Trinh ${ }^{1}$
}

Received: 25 January 2017/ Accepted: 24 April 2017/Published online: 3 May 2017

(C) The Author(s) 2017. This article is an open access publication

\begin{abstract}
In this paper, the analytical solution for static and vibration analysis the cross-ply laminated composite doubly curved shell panels with stiffeners resting on Winkler-Pasternak elastic foundation is presented. Based on the first-order shear deformation theory, using the smeared stiffeners technique, the motion equations are derived by applying the Hamilton's principle. The Navier's solution for shell panel with the simply supported boundary condition at all edges is presented. The accuracy of the present results is compared with those in the existing literature and shows good achievement. The effects of the number of stiffeners, stiffener's height-to-width ratio, and number of layers of cross-ply laminated composite shell panels on the fundamental frequencies and deflections of stiffened shell with and without the elastic foundation are investigated.
\end{abstract}

Keywords Static analysis - Vibration analysis · Cross-ply laminated composite - Doubly curved shallow shell . Stiffened shell - Elastic foundation · First-order shear deformation theory

Van Loi Nguyen

nguyenvanloi.n.v@gmail.com

Minh Tu Tran

tpnt2002@yahoo.com

Anh Tuan Trinh

tuan3115t1@yahoo.com

1 National University of Civil Engineering, 55 Giai Phong Road, Hanoi, Vietnam

\section{Introduction}

The composite materials, with excellent mechanical properties such as high-strength, light-weight, and tailor ability, make it ideal for aircraft, aerospace, and marine application. Stiffened shell structures are extensively used for the construction of a variety of engineering structures such as commercial vehicles, road tankers, aircraft fuselages, wings, naval vessels, ship hulls, submarine, etc. These structures are very often subjected to both static and dynamic loads. Hence, it becomes necessary to carry out a static and dynamic analysis to know the actual deformation and vibration characteristic of these structures.

Laminated composite shallow shells can be formed as rectangular, triangular, trapezoidal, circular, or any other plan forms and various types of curvatures such as singlycurved (e.g., cylindrical), double-curved (e.g., spherical), or other complex shapes such as turbo machinery blades.

During the years, many researches have been devoted to the static and dynamic analysis of doubly-curved shell structures. To determine the natural frequencies of simply supported cross-ply laminates cylindrical and doubly curved shells, a set of layerwise three-dimensional equations of motion in terms of displacements has been presented by Bhimaraddi (1991) and Huang (1995). Based on three-dimensional elasticity, Wu et al. (1996) performed the bending and stretching problem of doubly curved laminated composite shells. However, these models require huge computational cost for multilayered structures.

To overcome these difficulties, typically, researchers make simplifying assumptions for particular applications, and reduce the 3D shell problems to various $2 \mathrm{D}$ representations with reasonable accuracy. Among the 2D theories for composite laminated shells have been developed, which can be classified into two different models, such as the equivalent 
single-layer model and the layerwise model. Review articles and monographs oriented to such contributions may be found in works of Carrera (2002, 2003), Toorani and Lakis (2000), Noor and Burton (1990) and Qatu (2004) and Reddy (2004). The equivalent single-layer theories can be classified into the three major theories, i.e., the classical shell theory (CST), the first-order shear deformation theory (FSDT), and the higher order shear deformation theory (HSDT).

The classical shell theory (CST) is based on the KirchhoffLove assumptions, in which transverse normal and shear deformations are neglected. Depending on different assumptions made during the derivation of the strain-displacement relations, stress-strain relations, and the equilibrium equations, various thin shell theories may be obtained within the Kirchhoff-Love framework. Among the most common of these are Donnell's, Love's, Reissner's, Novozhilov's, Vlasov's, Sanders', and Flügge's shell theories, for which a detailed description can be found in the monograph by Leissa (1993). For moderately thick shells, the effects of transverse shear deformations must be considered, and the first-order shear deformation theories (FSDTs) are developed. Although the FSDT describes more realistic behavior of thin-to-moderately thick plates, the parabolic distribution of transverse shear stress through the thickness of the plate is not properly reflected, thus the shear correction factor is introduced. To avoid using shear correction factor, higher order shear deformation theories (HSDTs) are proposed. Exact solutions of the equations and fundamental frequencies for simply supported, doubly curved, cross-ply laminated shells were presented by Reddy (1984). Khdeir et al. (1989) and Librescu et al. (1989) developed a shear deformable theory of cross-ply laminated composite shallow shells using state space concept in conjunction with the Levy method to analyze their static, vibration, and buckling response. Khdeir and Reddy (1997) presented a model for the dynamic behavior of a laminated composite shallow arch from shallow shell theory. Free vibration of the arch is explored and exact natural frequencies of the third-order, second-order, first-order, and classical arch theories are determined for various boundary conditions.

The stiffeners are used to make shells with significantly increasing stiffness. Thus, to study these structures have been a remarkable trend of researchers in the recent years. The most powerful numerical tool for investigation of mechanical response of stiffened laminated composite shell structures with stiffeners is finite-element method: Bucalem and Bathe (1997), Scordelis and Lo (1964), Prusty (2003), Goswami and Mukhopadhyay (1994, 1995). The literature on the analytical free vibration analysis of stiffened shell is limited to a few published articles. Mustafa and Ali (1989) presented the energy method to determine the natural frequency of orthogonally stiffened isotropic cylindrical shells. Lee and Kim (1998) studied the vibration of the rotating composite cylindrical shell with orthogonal stiffeners using energy method. Zhao et al. (2002) used the Love's shell theory and the energy approach, and carried out the vibration analysis of simply supported rotating cross-ply laminated composite cylindrical shells with stringer and ring stiffeners. Bich et al. (2012, 2013), Bich and Nguyen (2012) used the smeared stiffeners technique, carried out the nonlinear analysis of eccentrically stiffened functionally graded cylindrical shell/panel, and eccentrically stiffened functionally graded shallow shell, (Bich and Van Tung 2011; Bich et al. 2011). Nonlinear dynamic response, buckling and post-buckling analysis of imperfect eccentrically stiffened functionally graded doubly curved shallow shell resting on elastic foundation in thermal environment using smeared technique are presented in works of Duc and Cong (2014), Duc (2013), Duc and Quan (2012). Orthotropic circular cylindrical shells with closed ends stiffened by equally spaced stringers and rings subjected to combinations of uniform internal pressure, constant temperature change, and axial load are investigated by Wang and Hsu (1985). Wattanasakulpong and Chaikittiratana (2015) investigated the free vibration characteristic of stiffened doubly curved shallow shells made of functionally graded materials under thermal environment. The first-order shear deformation theory is employed to derive the governing equations used for determining natural frequencies of the stiffened shells. The governing equations can be solved analytically to obtain exact solutions for this problem.

To the best of the authors' knowledge, there is no published research in the literature conducted on the static and free vibration analysis of the stiffened laminated composite doubly curved shells by analytical approach. Thus, the purpose of the present paper is to develop an analytical solution for static and vibration analysis of cross-ply laminated composite stiffened doubly curved shallow shell panels resting on elastic foundation. In this study, the first-order shear deformation theory and smeared technique are used. Parametric studies are carried out and may be useful for the preliminary design of dynamically loaded, stiffened laminated composite shells resting on elastic foundation.

\section{Theoretical formulations}

Consider a cross-ply laminated composite doubly curved shallow shell panel with stiffeners in coordinate $(x, y, z)$, as shown in Fig. 1; symbolize $a, b$, and $h$ are lengths of the shell in the $x$-direction, $y$-direction, and thickness of the shell, respectively. $R_{1}$ and $R_{2}$ are middle surface radii of curvature in the $x$ - and $y$-directions, respectively.

The displacement components at any point in the shell based on the first-order shear deformation theory (FSDT) 


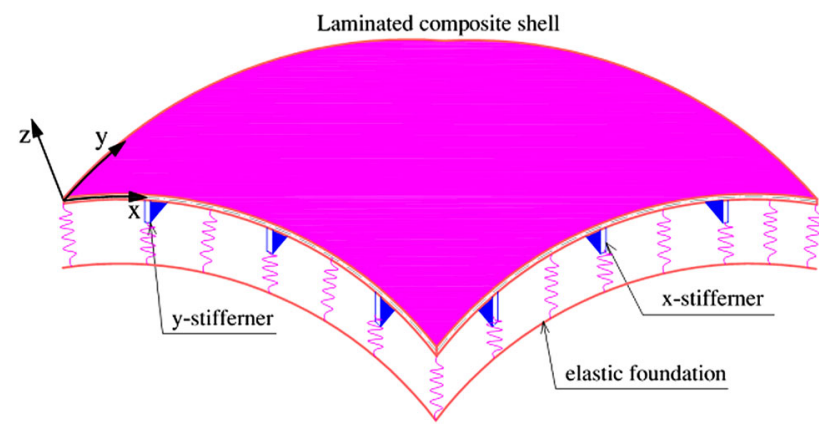

Fig. 1 Cross-ply laminated composite doubly curved shallow shell panel with $x$ - and $y$-stiffeners

are assumed as follows (Reddy 2004; Wattanasakulpong and Chaikittiratana 2015):

$$
\begin{aligned}
u(x, y, z, t) & =u_{0}(x, y, t)+z \phi_{x}(x, y, t) \\
v(x, y, z, t) & =v_{0}(x, y, t)+z \phi_{y}(x, y, t) \\
w(x, y, z, t) & =w_{0}(x, y, t)
\end{aligned}
$$

where $u_{0}, v_{0}$, and $w_{0}$ are the displacement components of a point on the mid-surface of shell corresponding to the $x-, y$ , and $z$-directions. In addition, $\phi_{x}$ and $\phi_{y}$ are the rotations of transverse normal about the $y$ - and $x$-axes. The linear strains are defined as

$$
\begin{aligned}
& \left\{\begin{array}{c}
\varepsilon_{x} \\
\varepsilon_{y} \\
\gamma_{x y}
\end{array}\right\}=\left\{\begin{array}{c}
\varepsilon_{x}^{0} \\
\varepsilon_{y}^{0} \\
\gamma_{x y}^{0}
\end{array}\right\}+z\left\{\begin{array}{c}
\kappa_{x} \\
\kappa_{y} \\
\kappa_{x y}
\end{array}\right\} ; \\
& \left\{\begin{array}{l}
\gamma_{y z} \\
\gamma_{x z}
\end{array}\right\}=\left\{\begin{array}{c}
\gamma_{y z}^{0} \\
\gamma_{x z}^{0}
\end{array}\right\}=\left\{\begin{array}{l}
\phi_{y}+\frac{\partial w_{0}}{\partial y}-\frac{\nu_{0}}{R_{2}} \\
\phi_{x}+\frac{\partial w_{0}}{\partial x}-\frac{u_{0}}{R_{1}}
\end{array}\right\}
\end{aligned}
$$

where

$$
\begin{aligned}
& \varepsilon_{x}^{0}=\frac{\partial u_{0}}{\partial x}+\frac{w_{0}}{R_{1}} ; \quad \varepsilon_{y}^{0}=\frac{\partial v_{0}}{\partial y}+\frac{w_{0}}{R_{2}} ; \quad \gamma_{x y}^{0}=\frac{\partial u_{0}}{\partial y}+\frac{\partial v_{0}}{\partial x} \\
& \kappa_{x}=\frac{\partial \phi_{x}}{\partial x} ; \quad \kappa_{y}=\frac{\partial \phi_{y}}{\partial y} ; \quad \kappa_{x y}=\frac{\partial \phi_{x}}{\partial y}+\frac{\partial \phi_{y}}{\partial x} .
\end{aligned}
$$

The constitutive equation of the $k$ th layer of laminated composite shell can be written as Reddy (2004)

$$
\left\{\begin{array}{c}
\sigma_{x} \\
\sigma_{y} \\
\sigma_{x y} \\
\sigma_{y z} \\
\sigma_{x z}
\end{array}\right\}_{k}=\left[\begin{array}{ccccc}
\bar{Q}_{11} & \bar{Q}_{12} & \bar{Q}_{16} & 0 & 0 \\
\bar{Q}_{12} & \bar{Q}_{22} & \bar{Q}_{26} & 0 & 0 \\
\bar{Q}_{16} & \bar{Q}_{26} & \bar{Q}_{66} & 0 & 0 \\
0 & 0 & 0 & \bar{Q}_{44} & \bar{Q}_{45} \\
0 & 0 & 0 & \bar{Q}_{45} & \bar{Q}_{55}
\end{array}\right]_{k}\left\{\begin{array}{c}
\varepsilon_{x} \\
\varepsilon_{y} \\
\gamma_{x y} \\
\gamma_{y z} \\
\gamma_{x z}
\end{array}\right\}_{k}
$$

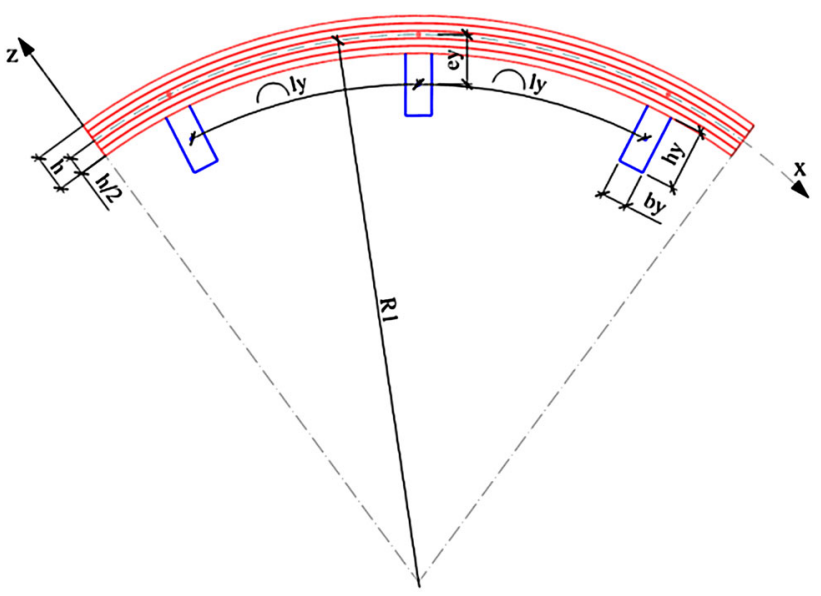

Fig. 2 Geometry of cross-ply laminated composite shallow shell panel with internal stiffeners in the $x-z$ plane

where $\sigma_{x}, \sigma_{y}, \sigma_{x y}, \sigma_{y z}, \sigma_{x z}$ and $\varepsilon_{x}, \varepsilon_{y}, \gamma_{x y}, \gamma_{y z}, \gamma_{x z}$ are the stress and strain components in the global coordinate system-laminate coordinates system $(x, y, z)$ of laminated composite shell; $\bar{Q}_{\mathrm{ij}}^{\prime} s$ are the transformed elastic constants with respect to the global coordinate system $(x, y, z)$, see more detail in Reddy (2004).

The geometry of the cross-ply laminated composite shallow shell panel with internal stiffeners in the $x-z$ is plane, as illustrated in Fig. 2. Denote $E_{x}, \rho_{x}, A_{x}, b_{x}$, $h_{x}, e_{x}, l_{x}$ and $E_{y}, \rho_{y}, A_{y}, b_{y}, h_{y}, e_{y}, l_{y}$ are Young's modulus, mass density of stiffener material, cross-sectional area, the width, the height of the cross section, the eccentricity, and the space between stiffeners along the $x$ - and $y$-directions, respectively. Stiffeners are assumed to be in uniaxial state of stress. Based on assumption that the stiffeners and the shell are perfectly bonded, the stress-strain relations of the stiffeners in the $x$ - and $y$ direction can be written as

$$
\begin{aligned}
& \sigma_{x x}^{(x)}=E_{x}\left(\frac{\partial u_{0}}{\partial x}+\frac{\partial \mathrm{w}_{0}}{R_{1}}\right)+E_{x} z \frac{\partial \phi_{x}}{\partial x} \\
& \sigma_{y y}^{(y)}=E_{y}\left(\frac{\partial v_{0}}{\partial y}+\frac{\partial \mathrm{w}_{0}}{R_{2}}\right)+E_{y} z \frac{\partial \phi_{y}}{\partial y} .
\end{aligned}
$$

The effects of the stiffness of the stiffeners are assumed to be smeared over the shell and the twist effect is ignored. Using the smeared stiffeners' technique, we have the internal moment and force resultants of the stiffened shell as follows (Bich et al. 2012; Wattanasakulpong and Chaikittiratana 2015): 


$$
\begin{aligned}
& \left\{\begin{array}{l}
N_{x x} \\
N_{y y} \\
N_{x y}
\end{array}\right\}=\int_{-h / 2}^{h / 2}\left\{\begin{array}{c}
\sigma_{x x} \\
\sigma_{y y} \\
\tau_{x y}
\end{array}\right\} \mathrm{d} z+\left\{\begin{array}{c}
\frac{1}{l_{x}} \int_{A_{x}} \sigma_{x x}^{(x)} \mathrm{d} A_{x} \\
\frac{1}{l_{y}} \int_{A_{y}} \sigma_{y y}^{(y)} \mathrm{d} A_{y} \\
0
\end{array}\right\} \\
& \left\{\begin{array}{l}
M_{x x} \\
M_{y y} \\
M_{x y}
\end{array}\right\}=\int_{-h / 2}^{h / 2}\left\{\begin{array}{c}
z \sigma_{x x} \\
z \sigma_{y y} \\
z \tau_{x y}
\end{array}\right\} \mathrm{d} z+\left\{\begin{array}{c}
\frac{1}{l_{x}} \int_{A_{x}} z \sigma_{x x}^{(x)} \mathrm{d} A_{x} \\
\frac{1}{l_{y}} \int_{A_{y}} z \sigma_{y y}^{(y)} \mathrm{d} A_{y} \\
0
\end{array}\right\} \\
& \left\{\begin{array}{c}
N_{x} \\
N_{y} \\
N_{x y} \\
M_{x} \\
M_{y} \\
M_{x y}
\end{array}\right\}=\left[\begin{array}{cccccc}
A_{11}^{\prime} & A_{12}^{\prime} & 0 & B_{11}^{\prime} & B_{12}^{\prime} & 0 \\
A_{12}^{\prime} & A_{22}^{\prime} & 0 & B_{12}^{\prime} & B_{22}^{\prime} & 0 \\
0 & 0 & A_{66}^{\prime} & 0 & 0 & B_{66}^{\prime} \\
B_{11}^{\prime} & B_{12}^{\prime} & 0 & D_{11}^{\prime} & D_{12}^{\prime} & 0 \\
B_{12}^{\prime} & B_{22}^{\prime} & 0 & D_{12}^{\prime} & D_{22}^{\prime} & 0 \\
0 & 0 & B_{66}^{\prime} & 0 & 0 & D_{66}^{\prime}
\end{array}\right]\left\{\begin{array}{c}
\varepsilon_{x}^{0} \\
\varepsilon_{y}^{0} \\
\gamma_{x y}^{0} \\
\kappa_{x} \\
\kappa_{y} \\
\kappa_{x y}
\end{array}\right\} ; \\
& \left\{\begin{array}{l}
Q_{y z} \\
Q_{x z}
\end{array}\right\}=k_{\mathrm{s}}\left[\begin{array}{cc}
A_{44} & 0 \\
0 & A_{55}
\end{array}\right]\left\{\begin{array}{c}
\gamma_{y z}^{0} \\
\gamma_{x z}^{0}
\end{array}\right\}
\end{aligned}
$$

where

$$
\begin{gathered}
A_{11}^{\prime}=A_{11}+\frac{E_{x} A_{x}}{l_{x}} ; \quad A_{12}^{\prime}=A_{12} ; \\
A_{22}^{\prime}=A_{22}+\frac{E_{y} A_{y}}{l_{y}} ; \quad A_{66}^{\prime}=A_{66} \\
B_{11}^{\prime}=B_{11}+\frac{E_{x} A_{x} e_{x}}{l_{x}} ; \quad B_{12}^{\prime}=B_{12} ; \\
B_{22}^{\prime}=B_{22}+\frac{E_{y} A_{y} e_{y}}{l_{y}} ; \quad B_{66}^{\prime}=B_{66} \\
D_{11}^{\prime}=D_{11}+\frac{E_{x} I_{x}}{l_{x}} ; \quad D_{12}^{\prime}=D_{12} ; \\
D_{22}^{\prime}=D_{22}+\frac{E_{y} I_{y}}{l_{y}} ; \quad D_{66}^{\prime}=D_{66}
\end{gathered}
$$

with

$$
\begin{gathered}
I_{x}=\frac{b_{x} h_{x}^{3}}{12}+e_{x}^{2} A_{x}, \quad I_{y}=\frac{b_{y} h_{y}^{3}}{12}+e_{y}^{2} A_{y} ; \\
e_{x}=\frac{h_{x}+h}{2} ; \quad e_{y}=\frac{h_{y}+h}{2} \\
\left\{\begin{array}{c}
\left(A_{i j}, B_{i j}, D_{i j}\right)=\int_{-h / 2}^{h / 2} Q_{i j}\left(1, z, z^{2}\right) \mathrm{d} z ; \\
(i j)=11,12,21,22,66
\end{array}\right. \\
A_{i j}=\int_{-h / 2}^{h / 2} Q_{i j} \mathrm{~d} z ; \quad(i j)=44,55 .
\end{gathered}
$$

The parameter $k_{\mathrm{s}}$ is the shear correction factor $\left(k_{\mathrm{s}}=5 /\right.$ 6). Appling Hamilton's principle, the governing equations of stiffened shell resting on the elastic foundation using the FSDT can be expressed as follows (Kiani et al. 2012; Reddy 2004):

$$
\begin{aligned}
& \frac{\partial N_{x x}}{\partial x}+\frac{\partial N_{x y}}{\partial y}+\frac{Q_{x z}}{R_{1}}=I_{0} \ddot{u}_{0}+I_{1} \ddot{\phi}_{x} ; \frac{\partial N_{x y}}{\partial x}+\frac{\partial N_{y y}}{\partial y}+\frac{Q_{y z}}{R_{2}}=I_{0} \ddot{v}_{0}+I_{1} \ddot{\phi}_{y} \\
& \frac{\partial Q_{x z}}{\partial x}+\frac{\partial Q_{y z}}{\partial y}-\frac{N_{x x}}{R_{1}}-\frac{N_{y y}}{R_{2}}-q-K_{\mathrm{w}} w_{0}+K_{p} \frac{\partial^{2} w_{0}}{\partial x^{2}}+K_{p} \frac{\partial^{2} w_{0}}{\partial y^{2}}=I_{0} \ddot{w}_{0} \\
& \frac{\partial M_{x x}}{\partial x}+\frac{\partial M_{x y}}{\partial y}-Q_{x z}=I_{1} \ddot{u}_{0}+I_{2} \ddot{\phi}_{x} ; \frac{\partial M_{x y}}{\partial x}+\frac{\partial M_{y y}}{\partial y}-Q_{y z}=I_{1} \ddot{v}_{0}+I_{2} \ddot{\phi}_{y}
\end{aligned}
$$

where

$$
\begin{aligned}
& I_{i}=\int_{-h / 2}^{h / 2} \rho_{e q} z^{i} \mathrm{~d} z \quad i=(0,1,2) ; \\
& \rho_{\mathrm{eq}}=\rho+\left(\frac{A_{x}}{l_{x} h}\right) \rho_{x}+\left(\frac{A_{y}}{l_{y} h}\right) \rho_{y}
\end{aligned}
$$

with $\rho$ is the material mass density of the laminated composite shell and $K_{\mathrm{w}}$ is the Winkler's elastic foundation coefficient and $K_{p}$ is a constant showing the effect of the shear interaction of vertical elements.

The above internal moment and force resultants are expressed in displacement terms using Eqs. (1-3) and (7). In addition, then, substituting the obtained results to Eq. (11), we get the equilibrium equations with respect to displacement components.

\section{Solution procedures}

In this study, analytical solution for the static and vibration analysis of the simply supported cross-ply laminated composite doubly curved shallow shell panels resting on elastic foundation is developed using Navier's solution. For symmetric or anti-symmetric cross-ply laminates, we have: $A_{16}^{\prime}=A_{26}^{\prime}=B_{16}^{\prime}=B_{26}^{\prime}=D_{16}^{\prime}=D_{26}^{\prime}=A_{45}^{\prime}=0$. The mathematical expressions for movable simply supported condition are given by Reddy (1984) and Kiani et al. (2012):

$$
\begin{aligned}
& N_{x}(0, y, t)=N_{x}(a, y, t)=M_{x}(0, y, t)=M_{x}(a, y, t)=0 \\
& w_{0}(0, y, t)=w_{0}(a, y, t)=v_{0}(0, y, t)=v_{0}(a, y, t)=0 \\
& N_{y}(x, 0, t)=N_{y}(x, b, t)=M_{y}(x, 0, t)=M_{y}(x, b, t)=0 \\
& w_{0}(x, 0, t)=w_{0}(x, b, t)=u_{0}(x, 0, t)=u_{0}(x, b, t)=0 \\
& \phi_{y}(0, y, t)=\phi_{y}(a, y, t)=\phi_{x}(x, 0, t)=\phi_{x}(x, b, t)=0 .
\end{aligned}
$$


The displacement expressions to satisfy boundary conditions (Eq. 13) and applied load are assumed as

$$
\left\{\begin{array}{c}
u_{0}(x, y, t) \\
v_{0}(x, y, t) \\
\mathrm{w}_{0}(x, y, t) \\
\phi_{x}(x, y, t) \\
\phi_{y}(x, y, t)
\end{array}\right\}=\sum_{m=1}^{\infty} \sum_{n=1}^{\infty}\left\{\begin{array}{c}
u_{m n}(t) \cos (\alpha x) \sin (\beta y) \\
v_{m n}(t) \sin (\alpha x) \cos (\beta y) \\
\mathrm{w}_{m n}(t) \sin (\alpha x) \sin (\beta y) \\
\phi_{x m n}(t) \cos (\alpha x) \sin (\beta y) \\
\phi_{y m n}(t) \sin (\alpha x) \cos (\beta y)
\end{array}\right\}
$$

$q(x, y, t)=\sum_{m=1}^{\infty} \sum_{n=1}^{\infty} \mathrm{q}_{m n}(t) \sin (\alpha x) \sin (\beta y)$

where $u_{m n}(t), v_{m n}(t), w_{m n}(t), \phi_{x m n}(t), \phi_{y m n}(t)$ are the coefficients; $\quad \alpha=m \pi / \mathrm{a} ; \beta=n \pi / b, \quad$ and $\quad q_{m n}(t)=$ $\frac{4}{a b} \int_{0}^{a} \int_{0}^{b} q(x, y, t) \sin (\alpha x) \sin (\beta y) \mathrm{d} x \mathrm{~d} y$.

Substituting Eqs. (14a, 14b) into the equilibrium equations with respect to displacement components of Eq. (11), it can be obtained as follows:

$[K]_{5 \times 5}\{\Delta(t)\}_{5 \times 1}+[M]_{5 \times 5}\{\ddot{\Delta}(t)\}_{5 \times 1}=\{F(t)\}_{5 \times 1}$

where

$$
\begin{aligned}
& \{\Delta(t)\}_{5 \times 1}=\left\{u_{m n}(t) v_{m n}(t) w_{m n}(t) \phi_{x m n}(t) \phi_{y m n}(t)\right\}^{\mathrm{T}} \\
& \{\ddot{\Delta}(t)\}_{5 \times 1}=\left\{\ddot{u}_{m n}(t) \ddot{v}_{m n}(t) \ddot{w}_{m n}(t) \ddot{\phi}_{x m n}(t) \ddot{\phi}_{y m n}(t)\right\}^{\mathrm{T}} \\
& \{F(t)\}_{5 \times 1}^{5 \times 1}=\left\{\begin{array}{lllll}
0 & 0 & q_{m n}(t) & 0 & 0
\end{array}\right\}^{\mathrm{T}} .
\end{aligned}
$$

The coefficients $K_{\mathrm{ij}}$ and $M_{\mathrm{ij}}$ are determined using symbolic toolbox in the MATLAB software, see more detail in "Appendix".

\section{Static analysis}

For static analysis, the solution can be obtained by solving the equations resulting from Eq. (15) by setting the time derivative terms to zero:

$$
[K]_{5 \times 5}\{\Delta\}_{5 \times 1}=\{F\}_{5 \times 1}
$$

where

$$
\begin{aligned}
& \{\Delta\}_{5 \times 1}=\left\{u_{m n} v_{m n} w_{m n} \phi_{x m n} \phi_{y m n}\right\}^{\mathrm{T}} \\
& \{F\}_{5 \times 1}=\left\{\begin{array}{lllll}
0 & 0 & q_{m n} & 0 & 0
\end{array}\right\}^{\mathrm{T}} .
\end{aligned}
$$

In this paper, the uniformly distributed transverse load over the surface of shell panel is considered: $q_{m n}=16 q_{0} /$ $\left(m n \pi^{2}\right), q_{0}$ is the intensity of the uniformly distributed load.

Solving Eq. (17), we can get the displacement components of Eq. (14a) and obtained the deflection of shell panel.

\section{Vibration analysis}

For vibration analysis, all applied loads are set to zero, $\{F(t)\}=\{0\}$, and we assume that the periodic solutions in Eq. (14a) are of the form:

$$
\begin{aligned}
u_{m n}(t) & =u_{m n} \mathrm{e}^{i \omega t} ; v_{m n}(t)=v_{m n} \mathrm{e}^{i \omega t} ; \quad \mathrm{w}_{m n}(t)=\mathrm{w}_{m n} \mathrm{e}^{i \omega t} ; \\
\phi_{x m n}(t) & =\phi_{x m n} \mathrm{e}^{i \omega t} ; \quad \phi_{y m n}(t)=\phi_{y m n} \mathrm{e}^{i \omega t}
\end{aligned}
$$

where $i$ is the imaginary unit, $i^{2}=-1 ; \omega$ is natural frequency.

In addition, then, substituting Eq. (14a) into Eq. (15), it can be obtained the equation:

$\left([K]_{5 \times 5}-\omega^{2}[M]_{5 \times 5}\right)\{\Delta\}_{5 \times 1}=\{0\}_{5 \times 1}$.

For a non-trivial solution, the determinant of the coefficient matrix of Eq. (20) should be zero. Solving the resulted determinant, we get the natural frequency, $\omega_{m n}$, corresponding to mode $(m, n)$. The smallest of the frequencies is called the fundamental frequency.

\section{Results and discussions}

\section{Validation}

In this section, the three examples for the verification of the present study are presented including the cross-ply laminated composite doubly curved shell without stiffeners, the cross-ply laminated composite plate without stiffeners resting on elastic foundation, and the stiffened isotropic plate without elastic foundation. It is noted that the doubly curved shell panel can changed to the various structural types by setting quantities as follows: $\frac{a}{R_{1}}=\frac{b}{R_{2}}=0$ for a flat plate; $\frac{a}{R_{1}}=0$ for a cylindrical shell panel; $\frac{a}{R_{1}}=\frac{b}{R_{2}}$ for a spherical shell panel.

The non-dimensional fundamental frequency, non-dimensional deflection, and non-dimensional elastic foundation parameters form is used:

$$
\begin{gathered}
\bar{\omega}=\omega a^{2} \sqrt{\rho / E_{2} / h^{2}} ; \bar{w}=\left(w h^{3} E_{2} / q_{0} a^{4}\right) \times 10^{3} ; \\
K_{0}=\frac{K_{w} a^{4}}{E_{2} h^{3}} ; J_{0}=\frac{K_{p} a^{2}}{E_{2} h^{3}} .
\end{gathered}
$$

First, the cross-ply laminated composite doubly curved shell without stiffeners is considered. The geometric parameters of the shell panel: $a / b=1 ; a /$ $h=100 ; R_{1}=R_{2}=R$ (for spherical shell); and the material properties of the shell: $E_{1}=25 E_{2} ; G_{13}=$ $G_{12}=0.5 E_{2} ; G_{23}=0.2 E_{2} ;$ and $v_{12}=0.25$. The non-dimensional fundamental frequencies $\bar{\omega}=\omega a^{2} \sqrt{\rho / E_{2} / h^{2}}$ 
and non-dimensional center deflections $\bar{w}=$ $\left(w h^{3} E_{2} / q_{0} a^{4}\right) \times 10^{3}$ of the cross-ply laminated composite doubly curved shell without stiffeners are calculated and listed in Table 1. The results are compared with those based on exact solution of Reddy (1984) using first-order shear deformation theory, too. From Table 1, it can be observed that the present results are identical with those of Reddy (1984).

Next, the cross-ply laminated composite plate without stiffeners resting on elastic foundation is considered. The geometric parameters of shell panel: $a=b=1 ; a / R_{1}=b /$ $R_{2}=0$ (for plate); lamination scheme $\left[0^{\circ} / 90^{\circ} / 0^{\circ}\right]$; and the material properties of the shell panel: $E_{1}=40 E_{2}$; $G_{13}=G_{12}=0.6 E_{2} ; G_{23}=0.5 E_{2} ;$ and $v_{12}=v_{13}=0.25$; $\rho=$ const. The fundamental frequencies of the cross-ply laminated composite plate resting and not resting on elastic foundation are calculated with various side-to-thickness ratios. The results are compared with those of Akavci (2007) and presented in Table 2. The non-dimensional fundamental frequencies as: $\bar{\omega}=\omega a^{2} \sqrt{\rho / E_{2} / h^{2}}$. The comparison shows good agreement (maximum discrepancy is $0.45 \%$ ).

The third example, the five natural frequencies of simply supported stiffened isotropic plate without elastic foundation are presented in Table 3 . The comparison between the present results with those reported by Szilard (1974) and Troitsky (1976) is made. The dimensions of the plate $(a /$ $\left.R_{1}=b / R_{2}=0\right) \quad$ are: $\quad a=0.6 \mathrm{~m} ; b=0.41 \mathrm{~m}$; and $h=0.00633 \mathrm{~m}$; the plate is stiffened with three stiffeners in the $x$-direction $\left(n_{x}=3\right)$ and five stiffeners in the $y$ direction $\left(n_{y}=5\right)$. The dimensions of stiffeners are $b_{x}=b_{y}=0.0127 \mathrm{~m}$ and $h_{x}=h_{y}=0.02222 \mathrm{~m}$, and the isotropic material properties of the shell and stiffeners are: $E=211 \mathrm{GPa} ; \rho=7830 \mathrm{~kg} / \mathrm{m}^{3}$; and $v=0.3$.

Results from Table 3 show good agreement, and the maximum discrepancy is $5.07 \%$ (Mode 3). Note that the results obtained by Szilard (1974) and Troitsky (1976) using the finite-element method. From the above verifications, it can be concluded that the present numerical results are reliable.

\section{Parametric study}

In the next investigations, the following geometric parameters and material properties of the shell panels are used: $\quad a=b=1 \mathrm{~m} ; b / h=50 ;$ and $\quad a / R_{1}=b / R_{2}=0.5$ (for spherical shell); $a / R_{1}=0$ and $b / R_{2}=0.5$ (for cylindrical shell); and $E_{1}=132.5 \mathrm{GPa} ; E_{2}=10.8 \mathrm{GPa} ; G_{13}=$ $G_{12}=5.7 \mathrm{GPa} ; G_{23}=3.4 \mathrm{GPa} ; v_{12}=0.24 ;$ and $\quad \rho=$ $1600 \mathrm{~kg} / \mathrm{m}^{3}$. The material properties of internal stiffeners

Table 1 Non-dimensional fundamental frequencies and center deflections for the simply supported cross-ply laminated composite spherical shell panel $\left(a / b=1, a / h=100, k_{s}=5 / 6\right)$

\begin{tabular}{|c|c|c|c|c|c|c|c|c|}
\hline \multirow[t]{3}{*}{$R / a$} & \multicolumn{4}{|l|}{$0^{\circ} / 90^{\circ}$} & \multicolumn{4}{|l|}{$0^{\circ} / 90^{\circ} / 0^{\circ}$} \\
\hline & \multicolumn{2}{|l|}{$\bar{\omega}$} & \multicolumn{2}{|l|}{$\bar{w}$} & \multicolumn{2}{|l|}{$\bar{\omega}$} & \multicolumn{2}{|l|}{$\bar{w}$} \\
\hline & Reddy (1984) & Present & Reddy (1984) & Present & Reddy (1984) & Present & Reddy (1984) & Present \\
\hline 3 & 46.002 & 46.002 & 0.6441 & 0.6441 & 47.265 & 47.265 & 0.6224 & 0.6224 \\
\hline 4 & 35.228 & 35.228 & 1.1412 & 1.1412 & 36.971 & 36.971 & 1.0443 & 1.0443 \\
\hline 5 & 28.825 & 28.825 & 1.7535 & 1.7535 & 30.993 & 30.993 & 1.5118 & 1.5118 \\
\hline 10 & 16.706 & 16.706 & 5.5428 & 5.5428 & 20.347 & 20.347 & 3.6445 & 3.6445 \\
\hline Plate & 9.687 & 9.687 & 16.980 & 16.980 & 15.183 & 15.183 & 6.6970 & 6.6970 \\
\hline
\end{tabular}

Table 2 Non-dimensional fundamental frequencies of the simply supported cross-ply laminated composite square plate resting on elastic foundation

\begin{tabular}{|c|c|c|c|c|c|c|c|}
\hline \multirow[t]{2}{*}{ Configuration } & \multirow[t]{2}{*}{$K_{0}$} & \multirow[t]{2}{*}{$J_{0}$} & \multirow[t]{2}{*}{ Method } & \multicolumn{4}{|l|}{$a / h$} \\
\hline & & & & 5 & 10 & 20 & 50 \\
\hline \multirow[t]{9}{*}[0^{\circ}/90^{\circ}/0^{\circ}]{} & 0 & 0 & Akavci (2007) & 10.265 & 14.700 & 17.481 & 18.640 \\
\hline & & & Present & 10.290 & 14.766 & 17.516 & 18.648 \\
\hline & & & Discrepancy (\%) & 0.24 & 0.45 & 0.20 & 0.04 \\
\hline & 100 & 0 & Akavci (2007) & 14.246 & 17.751 & 20.131 & 21.152 \\
\hline & & & Present & 14.263 & 17.806 & 20.161 & 21.158 \\
\hline & & & Discrepancy (\%) & 0.12 & 0.31 & 0.15 & 0.03 \\
\hline & 100 & 10 & Akavci (2007) & 19.880 & 22.595 & 24.535 & 25.390 \\
\hline & & & Present & 19.891 & 22.637 & 24.560 & 25.396 \\
\hline & & & Discrepancy $(\%)$ & 0.05 & 0.19 & 0.10 & 0.02 \\
\hline
\end{tabular}


Table 3 Natural frequencies $(\mathrm{Hz})$ of the simply supported isotropic plate with orthogonal stiffeners

Table 4 Fundamental frequencies $(\mathrm{Hz})$ of cross-ply laminated composite cylindrical shell panels resting on elastic foundation

\begin{tabular}{|c|c|c|c|c|c|}
\hline $\begin{array}{l}\text { Mode } \\
(m, n)\end{array}$ & $\begin{array}{l}1 \\
(1,1)\end{array}$ & $\begin{array}{l}2 \\
(2,1)\end{array}$ & $\begin{array}{l}3 \\
(1,2)\end{array}$ & $\begin{array}{l}4 \\
(3,1)\end{array}$ & $\begin{array}{l}5 \\
(2,2)\end{array}$ \\
\hline Szilard (1974) and Troitsky (1976) & 381.9 & 719.9 & 1339.8 & 1356.1 & 1512.4 \\
\hline Present & 368.3 & 690.4 & 1271.9 & 1329.0 & 1443.7 \\
\hline Discrepancy (\%) & 3.56 & 4.09 & 5.07 & 2.00 & 4.54 \\
\hline
\end{tabular}

\begin{tabular}{|c|c|c|c|c|c|c|c|c|}
\hline \multirow[t]{2}{*}{$K_{0}$} & \multirow[t]{2}{*}{$J_{0}$} & \multirow[t]{2}{*}{ Stiffener type } & \multicolumn{6}{|c|}{ Number of stiffeners } \\
\hline & & & 0 & 1 & 3 & 5 & 12 & 18 \\
\hline \multirow[t]{3}{*}{0} & 0 & Stringers ( $x$-direction) & 162.559 & 161.658 & 159.912 & 158.237 & 152.859 & 148.754 \\
\hline & & Rings ( $y$-direction) & 162.559 & 162.028 & 160.970 & 159.921 & 156.340 & 153.399 \\
\hline & & Orthogonal stiffeners & 162.559 & 161.152 & 158.539 & 156.153 & 149.127 & 144.246 \\
\hline \multirow[t]{3}{*}{100} & 10 & Stringers ( $x$-direction) & 215.091 & 213.500 & 210.443 & 207.537 & 198.394 & 191.595 \\
\hline & & Rings ( $y$-direction) & 215.091 & 213.788 & 211.270 & 208.860 & 201.162 & 195.324 \\
\hline & & Orthogonal stiffeners & 215.091 & 212.245 & 207.012 & 202.301 & 188.841 & 179.896 \\
\hline
\end{tabular}

Table 5 Fundamental frequencies $[\mathrm{Hz}]$ of cross-ply laminated composite spherical shell panels resting on elastic foundation

\begin{tabular}{|c|c|c|c|c|c|c|c|c|}
\hline \multirow[t]{2}{*}{$K_{0}$} & \multirow[t]{2}{*}{$J_{0}$} & \multirow[t]{2}{*}{ Stiffener type } & \multicolumn{6}{|c|}{ Number of stiffeners } \\
\hline & & & 0 & 1 & 3 & 5 & 12 & 18 \\
\hline \multirow[t]{3}{*}{0} & 0 & Stringers ( $x$-direction) & 287.146 & 284.565 & 279.620 & 274.942 & 260.361 & 249.664 \\
\hline & & Rings ( $y$-direction) & 287.146 & 284.743 & 280.131 & 275.762 & 262.092 & 252.012 \\
\hline & & Orthogonal stiffeners & 287.146 & 282.237 & 273.225 & 265.135 & 242.202 & 227.178 \\
\hline \multirow[t]{3}{*}{100} & 10 & Stringers ( $x$-direction) & 319.408 & 316.486 & 310.888 & 305.595 & 289.101 & 277.011 \\
\hline & & Rings (y-direction) & 319.408 & 316.647 & 311.352 & 306.338 & 290.673 & 279.142 \\
\hline & & Orthogonal stiffeners & 319.408 & 313.810 & 303.533 & 294.307 & 268.156 & 251.030 \\
\hline
\end{tabular}

\begin{tabular}{|c|c|c|c|c|c|c|c|c|}
\hline \multirow[t]{2}{*}{$K_{0}$} & \multirow[t]{2}{*}{$J_{0}$} & \multirow[t]{2}{*}{ Stiffener type } & \multicolumn{6}{|c|}{ Number of stiffeners } \\
\hline & & & 0 & 1 & 3 & 5 & 12 & 18 \\
\hline \multirow[t]{3}{*}{0} & 0 & Stringers ( $x$-direction) & 0.0450 & 0.0447 & 0.0440 & 0.0433 & 0.0412 & 0.0397 \\
\hline & & Rings ( $y$-direction) & 0.0450 & 0.0446 & 0.0437 & 0.0428 & 0.0399 & 0.0378 \\
\hline & & Orthogonal stiffeners & 0.0450 & 0.0442 & 0.0427 & 0.0413 & 0.0370 & 0.0341 \\
\hline \multirow[t]{3}{*}{100} & 10 & Stringers ( $x$-direction) & 0.0252 & 0.0251 & 0.0249 & 0.0247 & 0.0241 & 0.0235 \\
\hline & & Rings ( $y$-direction) & 0.0252 & 0.0251 & 0.0249 & 0.0246 & 0.0237 & 0.0230 \\
\hline & & Orthogonal stiffeners & 0.0252 & 0.0250 & 0.0246 & 0.0242 & 0.0227 & 0.0217 \\
\hline
\end{tabular}

Table 6 Center deflection (m) of cross-ply laminated composite cylindrical shell panels resting on elastic foundation scheme $\left[0^{\circ} / 90^{\circ} / 0^{\circ} / 90^{\circ}\right]$ are considered. Numbers of stiffeners in the $x$-direction (stringers), in the $y$-direction (rings), and orthogonal stiffeners $\left(n_{x}=n_{y}\right)$ are $n_{x}$, $n_{y}=(0 \div 18)$. The dimensions of the stiffeners are $b_{x}=b_{y}=h$ and $h_{x}=h_{y}=h$ (thickness of shell). The effects of the number of stiffeners on the fundamental frequency and central deflection of the laminated cross-ply spherical shell and cylindrical panels resting and not resting on elastic foundation are listed in Tables 4, 5, 6, and 7 and plotted in Figs. 3 and 4. Investigations have been carried out for the different stiffened ways: stringer along
In this investigation, the cross-ply laminated composite doubly curved shallow shell panels with lamination 
Table 7 Center deflection (m) of cross-ply laminated composite spherical shell panels resting on elastic foundation

\begin{tabular}{|c|c|c|c|c|c|c|c|c|}
\hline \multirow[t]{2}{*}{$K_{0}$} & \multirow[t]{2}{*}{$J_{0}$} & \multirow[t]{2}{*}{ Stiffener type } & \multicolumn{6}{|c|}{ Number of stiffeners } \\
\hline & & & 0 & 1 & 3 & 5 & 12 & 18 \\
\hline \multirow[t]{3}{*}{0} & 0 & Stringers ( $x$-direction) & 0.01325 & 0.01327 & 0.01330 & 0.01331 & 0.01329 & 0.01325 \\
\hline & & Rings (y-direction) & 0.01325 & 0.01327 & 0.01329 & 0.01329 & 0.01318 & 0.01310 \\
\hline & & Orthogonal stiffeners & 0.01325 & 0.01330 & 0.01335 & 0.01336 & 0.01326 & 0.01316 \\
\hline \multirow[t]{3}{*}{100} & 10 & Stringers ( $x$-direction) & 0.01065 & 0.01067 & 0.01069 & 0.01070 & 0.01071 & 0.01069 \\
\hline & & Rings ( $y$-direction) & 0.01065 & 0.01067 & 0.01069 & 0.01070 & 0.01065 & 0.01060 \\
\hline & & Orthogonal stiffeners & 0.01065 & 0.01069 & 0.01074 & 0.01076 & 0.01073 & 0.01068 \\
\hline
\end{tabular}

(a)

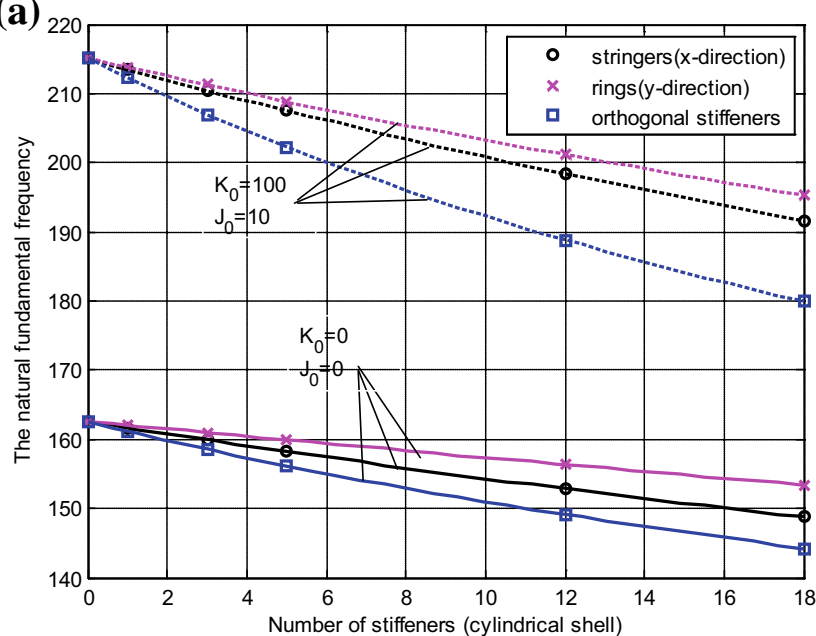

(b)

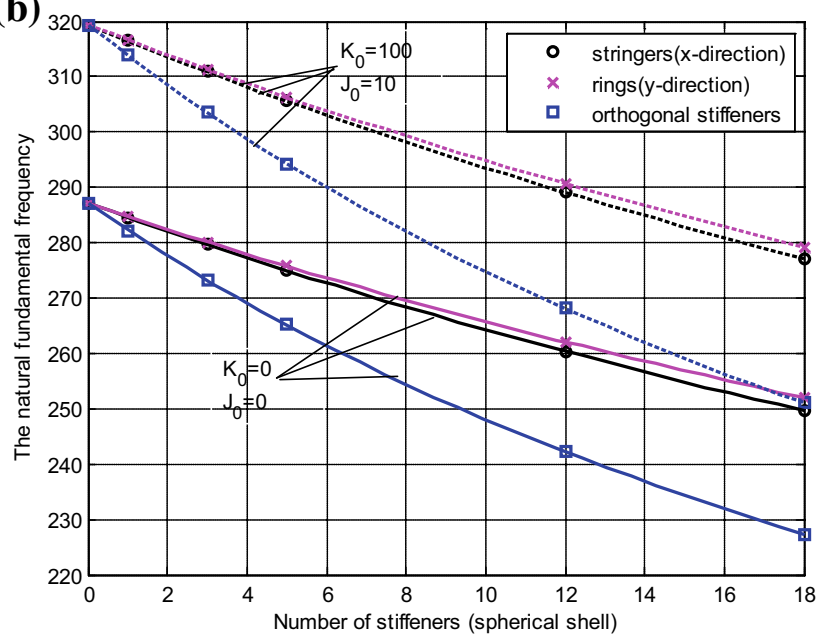

Fig. 3 Effects of number of stiffeners on the fundamental frequency $(\mathrm{Hz})$ of cross-ply shell panels resting and not resting on elastic foundation
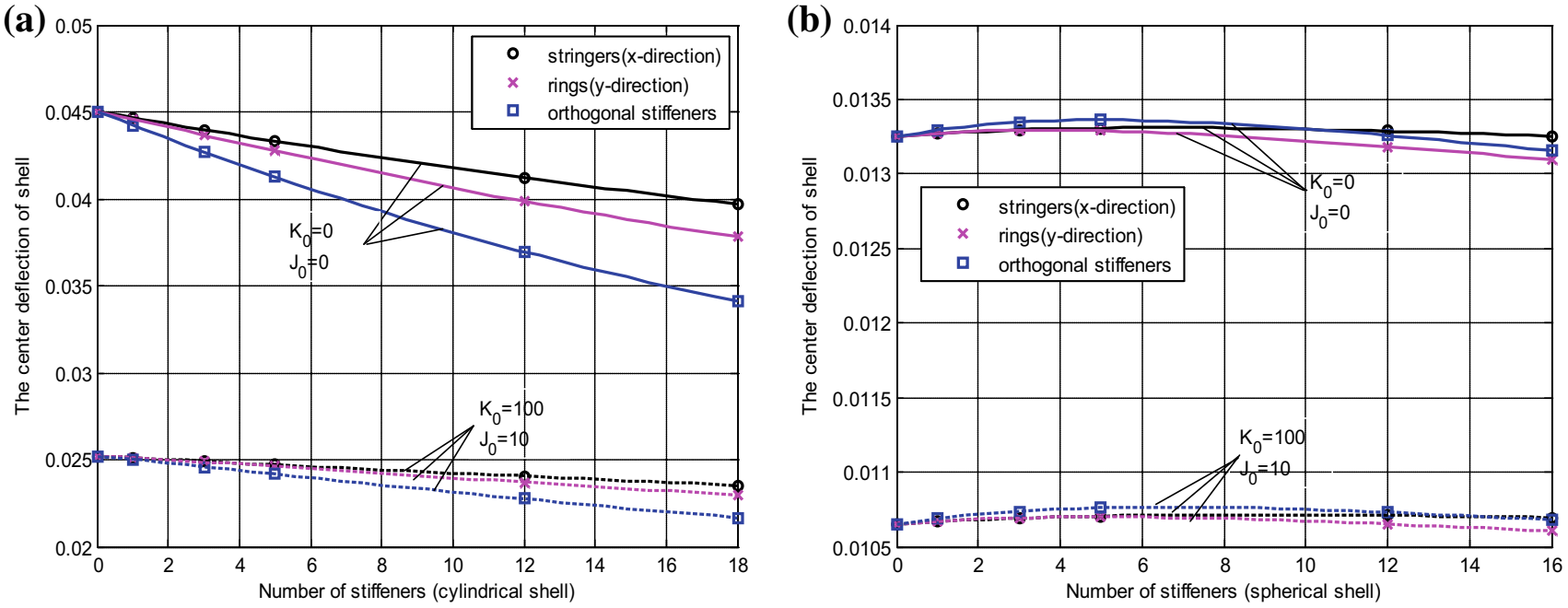

Fig. 4 Effects of number of stiffeners on the center deflection (m) of cross-ply shell panels resting and not resting on elastic foundation

$x$-direction only or $y$-direction only or orthogonal stiffeners.

From Fig. 3, it can be seen that the fundamental frequencies of both stiffened spherical and cylindrical shell panels decrease with increased number of stiffeners for both cases: resting and not resting on elastic foundation. This phenomenon can be explained by the fact that mass effect by stiffeners activates larger than stiffness effect.

In particular case, for stiffened spherical shell panel, at the beginning, the deflection of shell increases up and then 

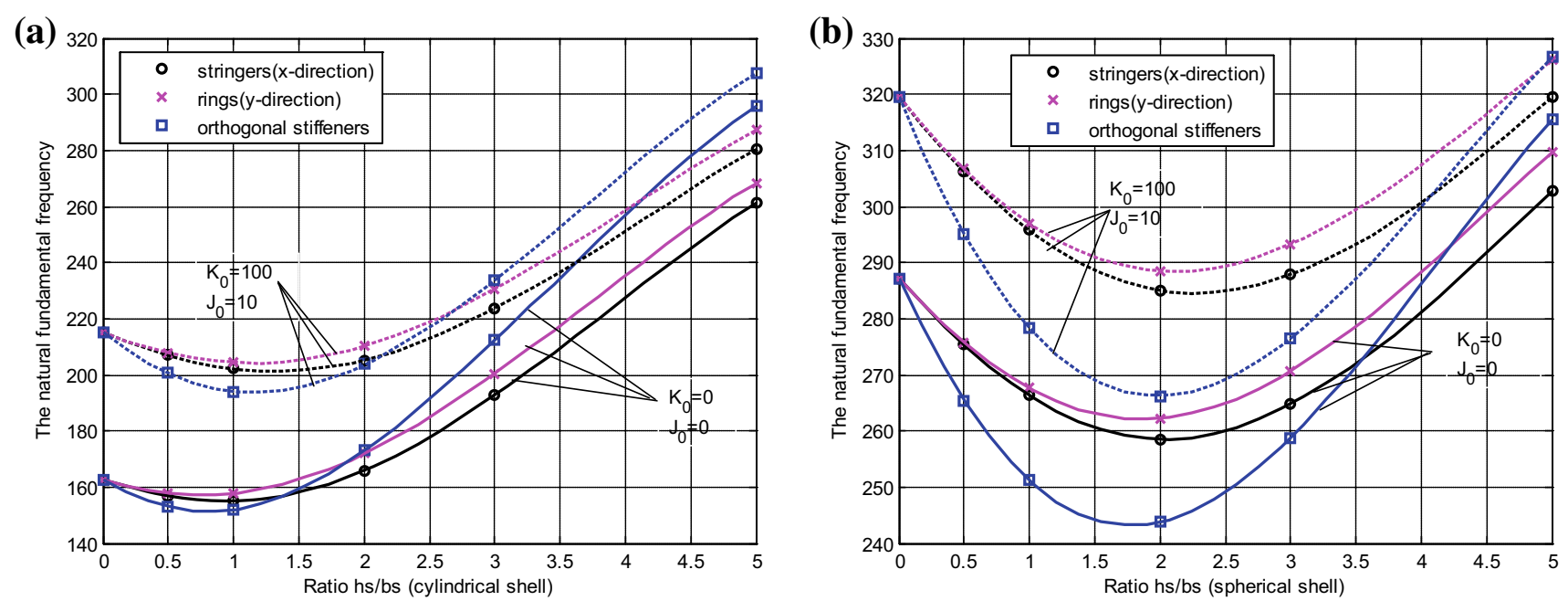

Fig. 5 Effects of stiffener's height-to-width ratio on the natural fundamental frequency (Hz) of the cross-ply shell panels resting on elastic foundation
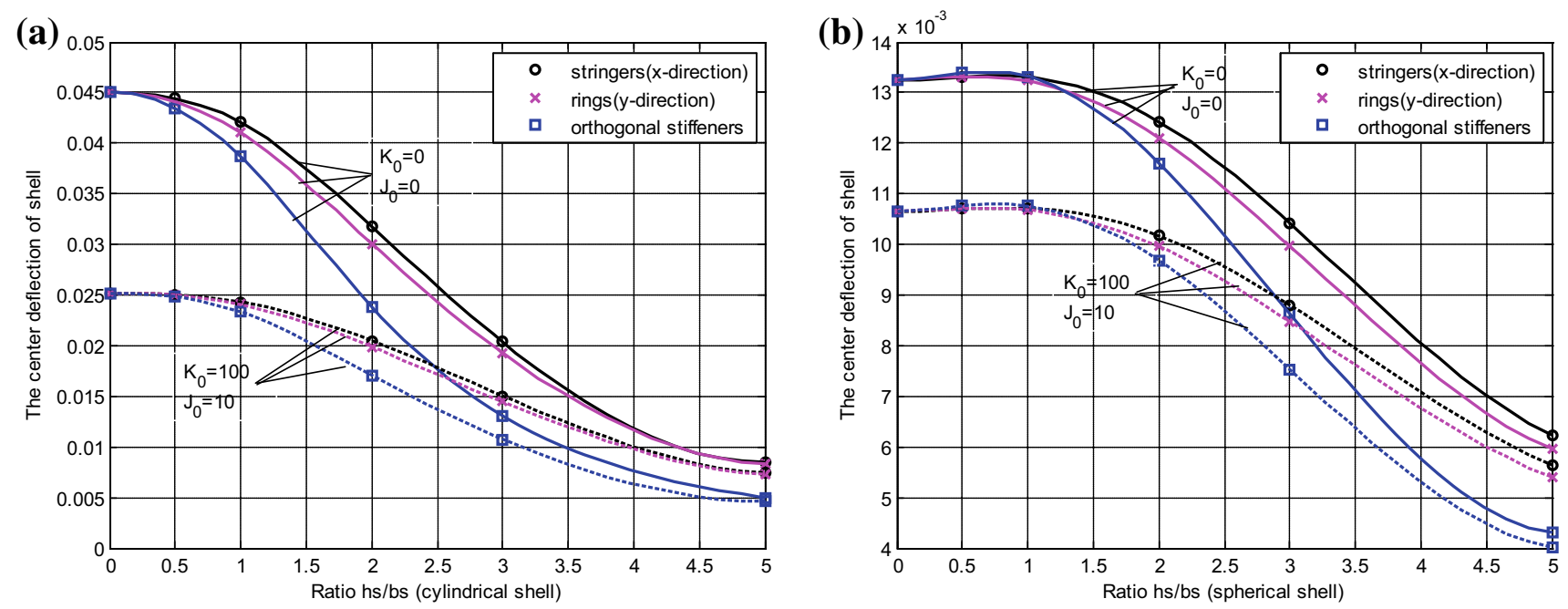

Fig. 6 Effects of stiffener's height-to-width ratio of stiffener on the center deflection $(\mathrm{m})$ of the cross-ply shell panels resting on elastic foundation

decreases down. Besides, the fundamental frequencies of stiffened shell panel with elastic foundation are higher than those without elastic foundation, but the deflections are smaller than those.

Figure 3 also shows that the fundamental frequency of both cylindrical shell panel and spherical shell panel with ring stiffeners is the highest (only for this dimension of stiffener and their material properties). Figure 4a depicts the decrease of central deflection with increased number of stiffener for cylindrical panel and shows that the deflection of cylindrical shell panel with orthogonal stiffeners is the smallest (i.e., the stiffest).
Effects of stiffener's height-to-width ratio on the fundamental frequency and central deflection

The effects of stiffener's height-to-width ratio $\left(h_{s} / b_{s}\right)$ on the fundamental frequencies and central deflections of the laminated cross-ply spherical shell and cylindrical shell panels are plotted in Figs. 5 and 6. The cross-ply shell panels with lamination scheme $\left[0^{\circ} / 90^{\circ} / 0^{\circ} / 90^{\circ}\right]$, the number of the stiffeners in the $x$-direction (stringers), the number of stiffeners in the $y$-direction (rings), and orthogonal stiffeners $\left(n_{x}=n_{y}\right)$ are nine stiffeners. The dimension of the 

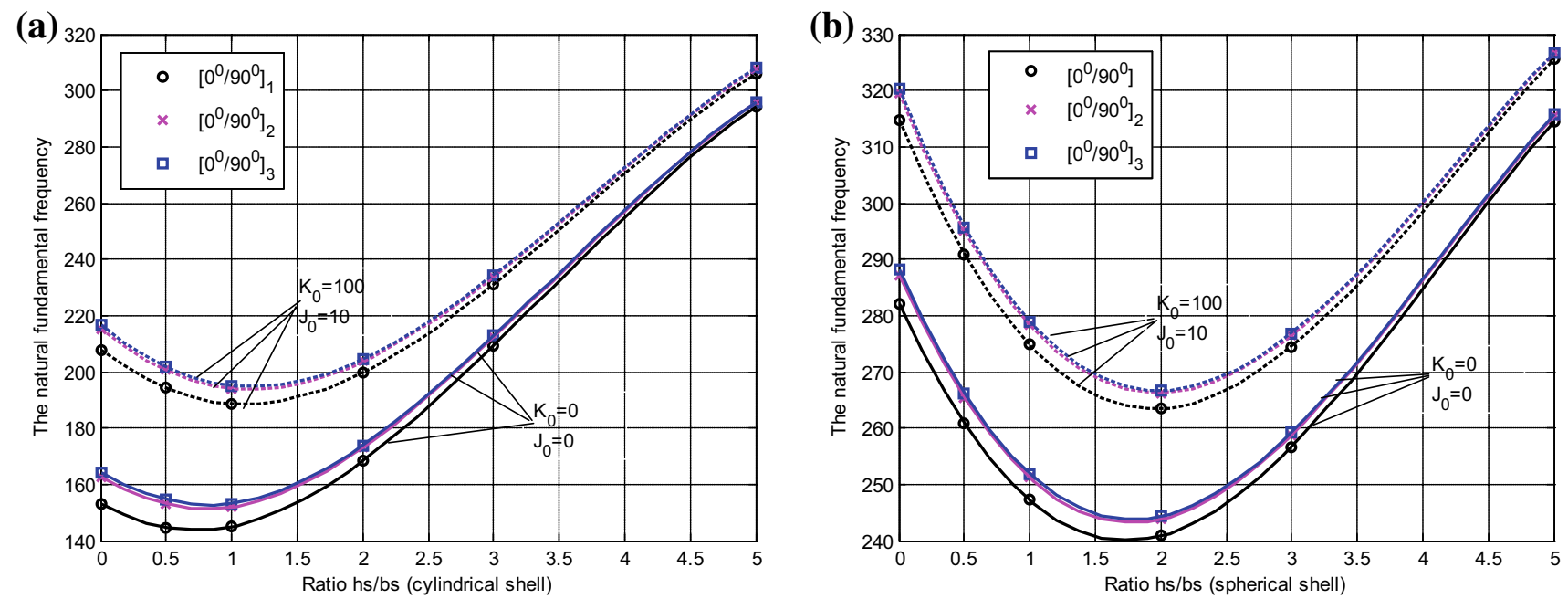

Fig. 7 Effects of the number of layers of cross-ply laminated composite on the fundamental frequency (Hz) of the shell panels with stiffeners resting on elastic foundation
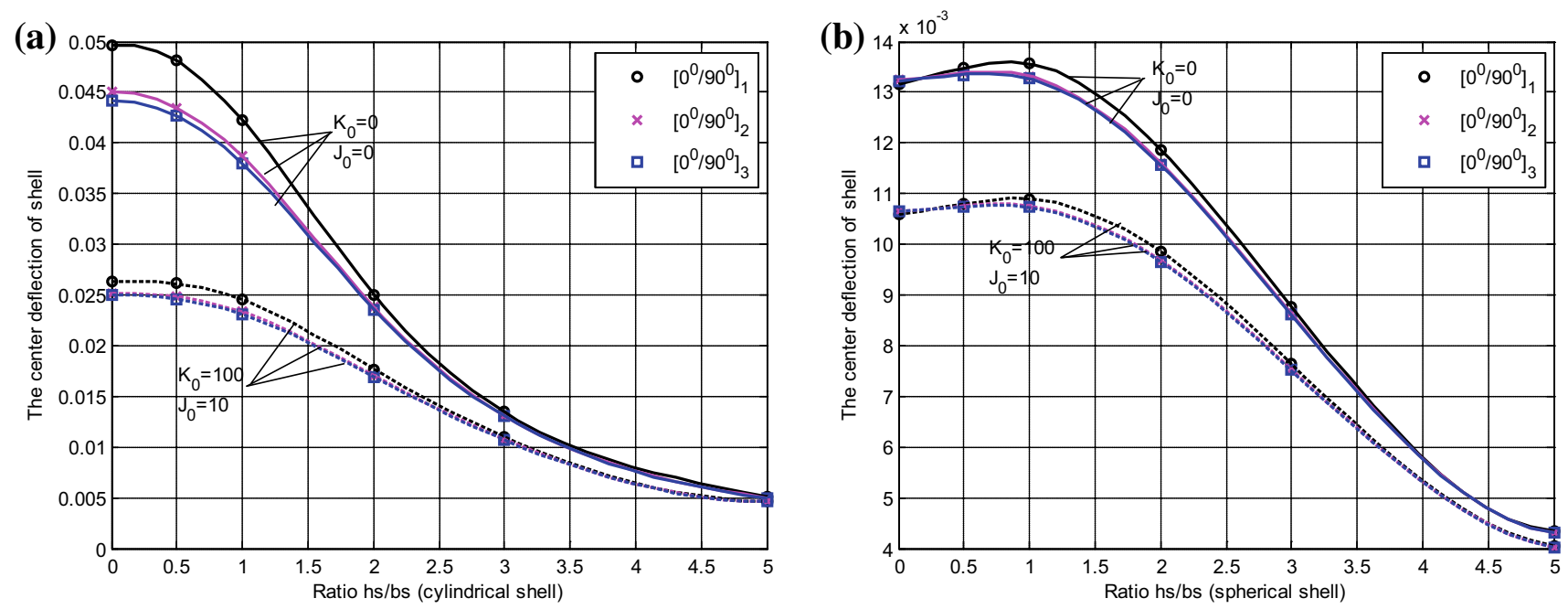

Fig. 8 Effects of the number of layers of cross-ply laminated composite on central deflection (m) of the shell panels with stiffeners resting on elastic foundation

stiffeners used is $b_{x}=b_{y}=h$ and $h_{x}=h_{y}=(0.5-5) h$; $h$ is the thickness of the shell.

As shown in Fig. 5, we see that the fundamental frequency of both stiffened cylindrical shell panel and spherical shell panel has a same trend of decrease to the minimum and then increase up, while the deflection of stiffened shell panels decreases, as shown in Fig. 6. Besides, the fundamental frequencies of stiffened shell panels with elastic foundation are higher than those without elastic foundation, while the deflections are smaller than those.

In Fig. 5a, b, it can be seen that the highest fundamental frequency of shell changes from shell panel with ring stiffeners to shell panel with orthogonal stiffeners.
However, the deflection of both cylindrical shell panel and spherical shell panel with orthogonal stiffeners is the smallest (the stiffest), see Fig. 6.

\section{Effects of the number of layers of cross-ply laminated} composite shell on the fundamental frequency and central deflection

Figures 7 and 8 show the effects of the numbers of layers of anti-symmetric cross-ply laminate composite shell on the fundamental frequency and central deflection of stiffened shell panels (cylindrical and spherical shell panels). The shell panels having nine stiffeners $\left(n_{x}=n_{y}=9\right)$ and lamination scheme $\left[0^{\circ} / 90^{\circ}\right]_{n}$ with constant thickness 
resting and not resting on the elastic foundation. The dimensions of the stiffeners are $b_{x}=b_{y}=h$ and $h_{y}=$ $h_{y}=(0-5) h$.

Both the figures indicate clearly that with the increase of number of shell layers, the fundamental frequencies are increased and the central deflections are decreased. This may be explained by the fact that the number of shell layers is increased, the laminate becomes stiffer.

In addition, from Figs. 3, 4, 5, 6, 7, and 8, it can be found that the fundamental natural frequency is increasing and the deflection is decreasing in the addition of the foundations.

\section{Conclusions}

In this work, the analytical solution for static and vibration analysis of stiffened cross-ply laminated composite doubly curved shallow shell panels resting on the elastic foundation with the simply supported boundary condition is presented. From the previous investigations, it can be noted that:

- For the vibration analysis, when the stiffener's heightto-width ratio increases, the highest fundamental frequency of shell changes from shell panel with ring stiffeners to shell panel with orthogonal stiffeners.

- For static analysis, when the stiffener's height-to-width ratio increases, the deflection of shell panel with orthogonal stiffeners (both cylindrical shell panel and spherical shell panel) is the smallest (stiffest).

- The elastic foundations make the fundamental natural frequency of stiffened cross-ply laminated composite doubly curved shallow shell increased and the deflection decreased.

- The number of shell layers is increased; the laminate doubly curved shell becomes stiffer.

Open Access This article is distributed under the terms of the Creative Commons Attribution 4.0 International License (http://crea tivecommons.org/licenses/by/4.0/), which permits unrestricted use, distribution, and reproduction in any medium, provided you give appropriate credit to the original author(s) and the source, provide a link to the Creative Commons license, and indicate if changes were made.

\section{Appendix}

The coefficients $K_{i j}, M_{i j}$ in Eq. (15):

$$
\begin{aligned}
K_{11}= & A_{11}^{\prime} \alpha^{2}+A_{66}^{\prime} \beta^{2}+\left(A_{55}^{\prime} k_{s}\right) / R_{1}^{2} \\
K_{12}= & A_{12}^{\prime} \alpha \beta+A_{66}^{\prime} \alpha \beta \\
K_{13}= & -\left(A_{11}^{\prime} \cdot \alpha+A_{55}^{\prime} \cdot \alpha \cdot k_{s}\right) / R_{1}-\left(A_{12}^{\prime} \cdot \alpha\right) / R_{2} \\
K_{14}= & B_{11}^{\prime} \cdot \alpha^{2}+B_{66}^{\prime} \cdot \beta^{2}-\left(A_{55}^{\prime} \cdot k_{s}\right) / R_{1} \\
K_{15}= & B_{12}^{\prime} \cdot \alpha \cdot \beta+B_{66}^{\prime} \cdot \alpha \cdot \beta \\
K_{22}= & A_{66}^{\prime} \alpha^{2}+A_{22}^{\prime} \beta^{2}+\left(A_{44}^{\prime} k_{s}\right) / R_{2}^{2} \\
K_{23}= & -\left(A_{22}^{\prime} \beta+A_{44}^{\prime} \beta k_{s}\right) / R_{2}-\left(A_{12}^{\prime} \beta\right) / R_{1} \\
K_{24}= & B_{12}^{\prime} \alpha \beta+B_{66}^{\prime} \alpha \beta \\
K_{25}= & B_{66}^{\prime} \alpha^{2}+B_{22}^{\prime} \beta^{2}-\left(A_{44}^{\prime} k_{s}\right) / R_{2} \\
K_{33}= & \left(A_{11}^{\prime}+K_{w} R_{1}^{2}+K_{p} R_{1}^{2} \alpha^{2}+K_{p} R_{1}^{2} \beta^{2}+A_{55}^{\prime} R_{1}^{2} \alpha^{2} k_{s}\right. \\
& \left.+A_{44}^{\prime} R_{1}^{2} \beta^{2} k_{s}\right) / R_{1}^{2} \\
& +\left(A_{22}^{\prime} R_{1}^{2}+2 A_{12}^{\prime} R_{2} R_{1}\right) /\left(R_{1}^{2} R_{2}^{2}\right) \\
K_{34}= & \left(-B_{11}^{\prime} R_{1} \alpha+A_{55}^{\prime} R_{1}^{2} \alpha k_{s}\right) / R_{1}^{2}-\left(B_{12}^{\prime} \alpha\right) / R_{2} \\
K_{35}= & \left(-B_{12}^{\prime} R_{1} \beta+A_{44}^{\prime} R_{1}^{2} \beta k_{s}\right) / R_{1}^{2}-\left(B_{22}^{\prime} \beta\right) / R_{2} \\
K_{44}= & D_{11}^{\prime} \alpha^{2}+D_{66}^{\prime} \beta^{2}+A_{55}^{\prime} k_{s} \\
K_{45}= & D_{12}^{\prime} \alpha \beta+D_{66}^{\prime} \alpha \beta \\
K_{55}= & D_{66}^{\prime} \alpha^{2}+D_{22}^{\prime} \beta^{2}+A_{44}^{\prime} k_{s} \\
M_{\mathrm{ij}}= & M_{j i} ; M_{11}=M_{22}=M_{33}=I_{0} ; \\
M_{44}= & M_{55}=I_{2} .
\end{aligned}
$$

\section{References}

Akavci S (2007) Buckling and free vibration analysis of symmetric and antisymmetric laminated composite plates on an elastic foundation. J Reinf Plast Compos 26(18):1907-1919

Bhimaraddi A (1991) Free vibration analysis of doubly curved shallow shells on rectangular planform using three-dimensional elasticity theory. Int J Solids Struct 27(7):897-913

Bich DH, Nguyen NX (2012) Nonlinear vibration of functionally graded circular cylindrical shells based on improved donnell equations. J Sound Vib 331(25):5488-5501

Bich DH, Van Tung H (2011) Non-linear axisymmetric response of functionally graded shallow spherical shells under uniform external pressure including temperature effects. Int J Non Linear Mech 46(9):1195-1204

Bich DH, Nam VH, Phuong NT (2011) Nonlinear postbuckling of eccentrically stiffened functionally graded plates and shallow shells. Vietnam J Mech 33(3):131-147

Bich DH, Van Dung D, Nam VH (2012) Nonlinear dynamical analysis of eccentrically stiffened functionally graded cylindrical panels. Compos Struct 94(8):2465-2473

Bich DH, Van Dung D, Nam VH, Phuong NT (2013) Nonlinear static and dynamic buckling analysis of imperfect eccentrically stiffened functionally graded circular cylindrical thin shells under axial compression. Int J Mech Sci 74:190-200

Bucalem M, Bathe K-J (1997) Finite element analysis of shell structures. Arch Comput Methods Eng 4(1):3-61 
Carrera E (2002) Theories and finite elements for multilayered, anisotropic, composite plates and shells. Arch Comput Methods Eng 9(2):87-140

Carrera E (2003) Historical review of zig-zag theories for multilayered plates and shells. Appl Mech Rev 56(3):287-308

Duc ND (2013) Nonlinear dynamic response of imperfect eccentrically stiffened fgm double curved shallow shells on elastic foundation. Compos Struct 99:88-96

Duc ND, Cong PH (2014) Nonlinear postbuckling of an eccentrically stiffened thin fgm plate resting on elastic foundations in thermal environments. Thin Walled Struct 75:103-112

Duc ND, Quan TQ (2012) Nonlinear stability analysis of doublecurved shallow fgm panels on elastic foundations in thermal environments. Mech Compos Mater 48(4):435-448

Goswami S, Mukhopadhyay M (1994) Finite element analysis of laminated composite stiffened shell. J Reinf Plast Compos 13(7):574-616

Goswami S, Mukhopadhyay M (1995) Finite element free vibration analysis of laminated composite stiffened shell. J Compos Mater 29(18):2388-2422

Huang N (1995) Exact analysis for three-dimensional free vibrations of cross-ply cylindrical and doubly-curved laminates. Acta Mech 108:23-34

Khdeir A, Reddy J (1997) Free and forced vibration of cross-ply laminated composite shallow arches. Int $\mathrm{J}$ Solids Struct 34(10):1217-1234

Khdeir A, Librescu L, Frederick D (1989) A shear deformable theory of laminated composite shallow shell-type panels and their response analysis II: static response. Acta Mech 77(1-2):1-12

Kiani Y, Akbarzadeh A, Chen Z, Eslami M (2012) Static and dynamic analysis of an fgm doubly curved panel resting on the pasternaktype elastic foundation. Compos Struct 94(8):2474-2484

Lee Y-S, Kim Y-W (1998) Vibration analysis of rotating composite cylindrical shells with orthogonal stiffeners. Comput Struct 69(2):271-281

Leissa AW (1993) Vibration of shells. Acoustical Society of America, New York
Librescu L, Khdeir A, Frederick D (1989) A shear deformable theory of laminated composite shallow shell-type panels and their response analysis I: free vibration and buckling. Acta Mech 76(1-2):1-33

Mustafa B, Ali R (1989) An energy method for free vibration analysis of stiffened circular cylindrical shells. Comput Struct 32(2):355-363

Noor AK, Burton WS (1990) Assessment of computational models for multilayered composite shells. Appl Mech Rev 43(4):67-97

Prusty BG (2003) Linear static analysis of composite hat-stiffened laminated shells using finite elements. Finite Elem Anal Des 39(12):1125-1138

Qatu MS (2004) Vibration of laminated shells and plates. Elsevier, New York

Reddy JN (1984) Exact solutions of moderately thick laminated shells. J Eng Mech 110(5):794-809

Reddy JN (2004) Mechanics of laminated composite plates and shells: theory and analysis. CRC press, Boca Raton, FL, USA

Scordelis A, Lo K (1964) Computer analysis of cylindrical shells. J Proc 61(5):539-562

Szilard R (1974) Theory and analysis of plates. Prentice-Hall, Englewood Cliffs, New Jersey

Toorani M, Lakis A (2000) General equations of anisotropic plates and shells including transverse shear deformations, rotary inertia and initial curvature effects. J Sound Vib 237(4):561-615

Troitsky M (1976) Stiffened plates. Elsevier, New York

Wang J-S, Hsu T-M (1985) Discrete analysis of stiffened composite cylindrical shells. AIAA J 23(11):1753-1761

Wattanasakulpong N, Chaikittiratana A (2015) An analytical investigation on free vibration of FGM doubly curved shallow shells with stiffeners under thermal environment. Aerosp Sci Technol 40:181-190

Wu C-P, Tarn J-Q, Chi S-M (1996) Three-dimensional analysis of doubly curved laminated shells. J Eng Mech 122(5):391-401

Zhao X, Liew K, Ng T (2002) Vibrations of rotating cross-ply laminated circular cylindrical shells with stringer and ring stiffeners. Int J Solids Struct 39(2):529-545 